\title{
Angiotensin III increases monocyte chemoattrac- tant protein-1 expression in cultured human proximal tubular epithelial cells
}

\author{
Hyung Wook Kim¹, Young Ok Kim², Sun Ae Yoon ${ }^{2}$, Jeong-Sun Han ${ }^{3}$,Hyun-Bae Chun ${ }^{4}$, and Young Soo Kim²
}

\begin{abstract}
${ }^{1}$ Division of Nephrology, Department of Internal Medicine, College of Medicine, St. Vincent's Hospital, The Catholic University of Korea, Suwon; ${ }^{2}$ Division of Nephrology, Department of Internal Medicine, College of Medicine, Uijeongbu St. Mary's Hospital, The Catholic University of Korea, Uijeongbu; ${ }^{3}$ Renal Research Laboratory, Division of Nephrology, Department of Internal Medicine, College of Medicine, The Catholic University of Korea, Seoul, Korea; ${ }^{4}$ Department of Medicine, Stony Brook University of New York, Stony Brook, NY, USA
\end{abstract}

Received: July 2, 2014 Revised : August 26, 2014 Accepted: August 26, 2014

\section{Correspondence to}

Young Soo Kim, M.D.

Division of Nephrology,

Department of Internal Medicine, College of Medicine, Uijeongbu St. Mary's Hospital, The Catholic

University of Korea, 271

Cheonbo-ro, Uijeongbu 11765, Korea

Tel: $+82-31-820-3583$

Fax: +82-31-847-2719

E-mail: dr52916@catholic.ac.kr
Background/Aims: We investigated whether angiotensin III (Ang III) is involved in monocyte recruitment through regulation of the chemokine monocyte chemoattractant protein-1 (MCP-1) in cultured human proximal tubular epithelial cells (HK-2 cells).

Methods: We measured MCP-1 levels in HK-2 cells that had been treated with various concentrations of Ang III and Ang II type-1 (AT1) receptor antagonists at various time points. The phosphorylation states of $\mathrm{p}_{3} 8$, c-Jun N-terminal kinases (JNK), and extracellular-signal-regulated kinases were measured in Ang III-treated cells to explore the mitogen-activated protein kinase (MAPK) pathway. MCP-1 levels in HK-2 cell-conditioned media were measured after pre-treatment with the transcription factor inhibitors curcumin or pyrrolidine dithiocarbamate.

Results: Ang III increased MCP-1 protein production in dose- and time-dependent manners in HK-2 cells, which was inhibited by the ATr receptor blocker losartan. p38 MAPK activity increased significantly in HK-2 cells exposed to Ang III for 30 minutes, and was sustained at higher levels after 60 minutes $(p<0.05)$. Total phosphorylated JNK protein levels tended to increase 20 minutes after stimulation with Ang III. Pre-treatment with a p3 8 inhibitor, a JNK inhibitor, or curcumin significantly inhibited Ang III-induced MCP-1 production.

Conclusions: Ang III increases MCP-1 synthesis via stimulation of intracellular p38 and JNK MAPK signaling activity and subsequent activated protein-1 transcriptional activity in HK-2 cells.

Keywords: Angiotensin III; Kidney tubules; Chemokine CCL2; Mitogen-activated protein kinases; Transcription factors

\section{INTRODUCTION}

The renin-angiotensin system (RAS) regulates homeostatic mechanisms such as water and electrolyte balance, blood pressure [1-3], and the aging process [4]. Chronic RAS activation is commonly related to cardiovascular dysfunction and damage to target organs, including the blood vessels, heart, and kidneys [5].

RAS activation causes an inflammatory response by inducing the activities of several cytokines, chemokines, and transcription factors $[6,7]$. Angiotensin (Ang) II commonly increases the expression of adhesion molecules and cytokines, such as selectins, intercellular adhesion molecule-1, vascular cell adhesion molecule-1, 
and chemokine (C-C motif) ligand 2/monocyte chemoattractant protein-1 (MCP-1) in target cells, resulting in the recruitment of inflammatory cells from the blood to tissues $[8,9]$.

Metabolic products such as Ang III, Ang IV, and Ang 1 to 7 , have been discovered by investigating enzymatic degradation of Ang II in kidney tissues [10]. These products bind to two major receptor subtypes that mediate RAS actions, such as the Ang II type-1 (AT1) and AT2 receptors. However, they also serve as ligands to other receptors, such as the Mas receptor or insulin-regulated aminopeptidase, which have different functions. These receptors have been detected in various regions of the kidney, and their specific roles and functions have been investigated [11-13].

Ang III has similar activity to that of Ang II, and its receptor is located in renal proximal tubular epithelial cells $[14,15]$. Additionally, aminopeptidase A, present on the surface of podocytes, mesangial cells, and proximal tubular epithelial cells, degrades Ang II into Ang III $[16,17]$. This degradation product increases the secretion of angiotensinogen and transforming growth factor- $\beta$, resulting in vascular contraction and renin secretion, linked to inflammation and fibrosis in various kidney diseases $[12,18,19]$. However, the details of Ang III function have not been fully elucidated.

MCP-1 is a C-C chemokine with strong chemotactic activity for monocytes, $\mathrm{T}$ lymphocytes, and basophils and is expressed by most cells in the kidney, such as mesangial, glomerular epithelial, and proximal tubular epithelial cells $[20,21]$. In addition, MCP-1 is synthesized and released by vascular, cardiac, and renal cells in response to hemodynamic (shear stress, blood flow, or oxidative stress) and humoral stimuli (such as Ang II and endothelin-1) [22].

Mitogen-activated protein kinases (MAPK) are serine/ threonine-specific protein kinases that respond to extracellular stimuli (mitogens, osmotic stress, heat shock, and pro-inflammatory cytokines), and regulate various cellular activities, such as gene expression, mitosis, differentiation, proliferation, and cell survival/apoptosis [23]. p38, extracellular signal-regulated kinases (ERK), and c-Jun N-terminal kinase (JNK) are well-known MAPKs that regulate MCP-1 expression in various kidney diseases, such as proliferative glomerulonephritis and diabetic nephropathy [24-28].
In the present study, we investigated whether Ang III affects MCP-1 expression and activation of transcrip-

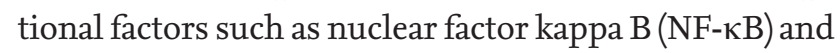
activating protein-1 (AP-1) in cultured human proximal tubular HK-2 cells. We also investigated MAPK signaling as an intracellular pathway related to MCP-1 expression by Ang III.

\section{METHODS}

\section{Materials}

Ang II and III were purchased from Sigma (St. Louis, MO, USA). The primary antibodies used for Western blot were anti-p38, anti-JNK, and anti-ERK rabbit polyclonals (Cell Signaling Technology Inc., Beverly, MA, USA). Inhibitors of p38 MAPK (SB202190), ERK (PD98059), and JNK (SP600125) were purchased from Sigma.

To evaluate the relation of transcription factors to increases in MCP-1, we used the AP-1 inhibitor curcumin (Sigma) and the NF-кB inhibitor pyrrolidine dithiocarbamate (PDTC, Sigma).

\section{Cell cultures}

HK-2 cells and immortalized human proximal tubular epithelial cells were purchased from the American Type Culture Collection (Rockville, MD, USA). Cells were seeded at a density of $1 \times 10^{4}$ cells/well into 24 -well culture plates containing Dulbecco's Modified Eagle's medium-F12 (Gibco BRL, Rockville, MD, USA), supplemented with $2 \mathrm{mM}$ L-glutamine, penicillin $(100 \mathrm{U} / \mathrm{mL}) /$ streptomycin $(100 \mu \mathrm{g} / \mathrm{mL})$, and $10 \%$ fetal bovine serum in humidified air at $37^{\circ} \mathrm{C}$ with $5 \% \mathrm{CO}_{2}$. Medium was changed 48 hours after plating. Cells were cultured to $\pm 80 \%$ confluency, washed twice with HBSS, and starved in serum-free medium for 24 hours [29].

\section{MCP-1 enzyme-linked immunosorbent assay}

Mouse anti-human MCP-1 antibody ( $2 \mu \mathrm{g} / \mathrm{mL}$; R\&D Systems, Minneapolis, MN, USA) was used as the capture antibody, and $1 \mu \mathrm{g} / \mathrm{mL}$ biotinylated goat anti-human MCP-1 antibody (R\&D Systems) was used for detection. The TMB micro-well peroxidase substrate system (Kirkegaard \& Perry Laboratories, Inc., Gaithersburg, $\mathrm{MD}, \mathrm{USA}$ ) was used as the enzyme substrate, and the reaction was measured at $\mathrm{OD}_{450}$. 


\section{Cell viability}

HK-2 cell viability was assessed by measuring lactate dehydrogenase (LDH) release into the culture medium using a LDH cytotoxicity detection kit according to the manufacturer's protocol (Takara Biomedical, Kyoto, Japan).

\section{Western blot analysis}

Confluent cells $\left(1 \times 10^{5}\right)$ were starved for 24 hours and pre-incubated with Ang III $\left(10^{-7} \mathrm{M}\right)$ for various times $(5,10,20,30$, and 60 minutes). Treated cells were lysed for 10 minutes on ice in lysis buffer $(50 \mathrm{mM}$ Tris, $\mathrm{pH}$ 7.5, $40 \mathrm{mM} \mathrm{NaCl}, 1 \%$ Triton X-100, 2 mM ethylenediaminetetraacetic acid, $1 \mu \mathrm{g} / \mathrm{mL}$ leupeptin, $2 \mathrm{mM}$ dithiothreitol, and $1 \mathrm{mM}$ phenylmethylsulfonyl fluoride). Lysates were cleared by centrifugation at $14,000 \times \mathrm{g}\left(4^{\circ} \mathrm{C}\right)$ for 10 minutes. Protein levels were quantified using the Bradford assay. Equal amounts of lysates were separated by $10 \%$ sodium dodecyl sulfate-polyacrylamide gel electrophoresis and electrotransferred to Bio-Blot nitrocellulose membranes (Bio-Rad Laboratories Inc., Hercules, CA, USA). Membranes were blocked with TBS ( $\mathrm{pH}$ 7.6)/5\% nonfat dry milk/0.05\% Tween 20 and blotted with the indicated antibodies (against phosphorylated and non-phosphorylated p38, JNK, and ERK) at $4^{\circ} \mathrm{C}$ overnight, then 1:1,000 diluted horseradish peroxidase-conjugated secondary antibody (Amersham Bioscience, Little Chalfont, UK) at room temperature for 1 hour and visualized with an enhanced chemiluminescence kit (Amersham Bioscience).

\section{Statistics}

Data are expressed as the mean \pm standard error. Multiple groups were compared using the Kruskall-Wallis test. Comparisons between multiple timepoints were performed by repeated-measures analysis of variance. A $p<0.05$ was significant.

\section{RESULTS}

\section{Ang III increases MCP-1 production in HK-2 cells}

Ang III significantly increased MCP-1 protein levels in HK-2 cells in a concentration-dependent manner, which was significantly inhibited by the AT1 receptor antagonist losartan $(p<0.05)$ (Fig. 1). MCP-1 protein lev- els were also measured in the supernatants of HK-2 cells stimulated with Ang III $\left(10^{-7} \mathrm{M}\right)$ for various time points $(8,12,24$, and 48 hours). Production of MCP-1 by HK-2 cells was significantly stimulated by Ang III after 48 and 72 hours $(p<0.05)$ (Fig. 2 ).

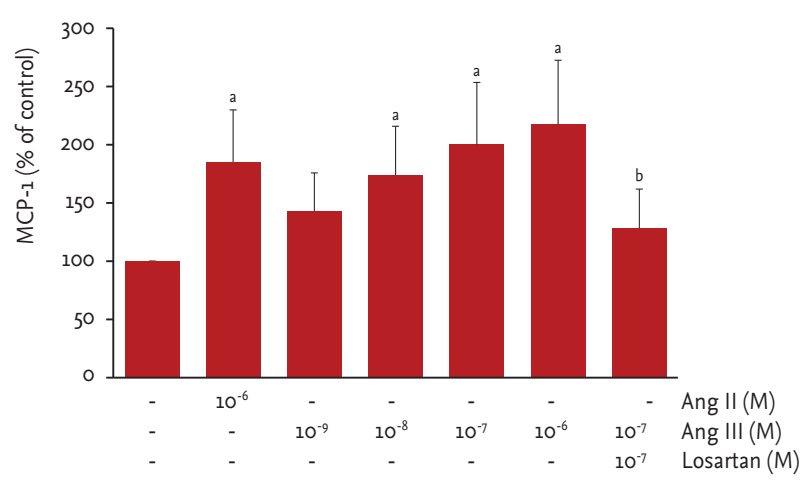

Figure 1. Angiotensin III (Ang III)-induced monocyte chemoattractant protein-1 (MCP-1) production in HK-2 cells via the Ang II type-1 (AT1) receptor. HK-2 cells were treated with Ang II $\left(10^{-6} \mathrm{M}\right)$ and Ang III $\left(10^{-9}\right.$ to $\left.10^{-6} \mathrm{M}\right)$ for 48 hours in the presence or absence of the ATr receptor antagonist losartan $\left(10^{-7} \mathrm{M}\right)$. MCP-1 protein in conditioned medium was quantified by enzyme-linked immunosorbent assay. Results are expressed as the percentage increase over untreated cells. Results are shown as mean \pm standard error of mean from six independent experiments. ${ }^{a} p<0.05$ vs. untreated cells, ${ }^{b} p<0.05$ vs. Ang III $\left(10^{-7} \mathrm{M}\right)$-treated cells.

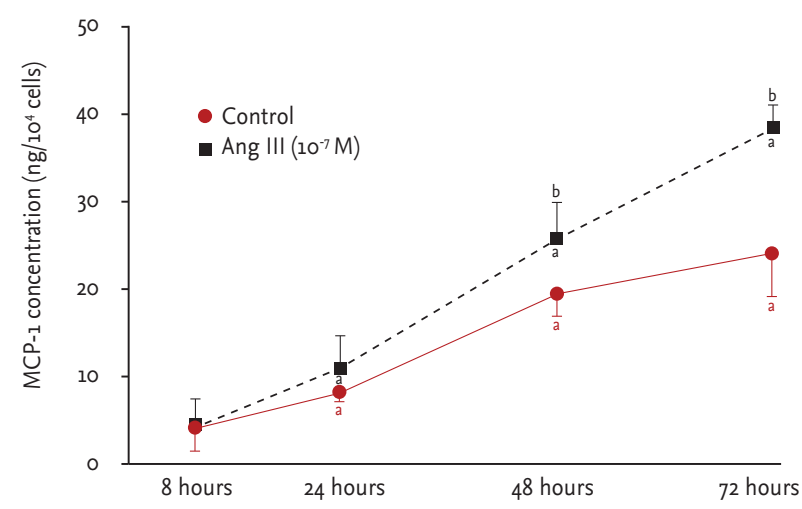

Figure 2. Angiotensin III (Ang III)-stimulated monocyte chemoattractant protein-1 (MCP-1) production in $\mathrm{HK}-2$ cells. Cells were incubated for the indicated times in the presence or absence of Ang III. MCP-1 protein in culture medium was quantified by enzyme-linked immunosorbent assay. Results are shown as mean \pm SEM from six independent experiments. Lactate dehydrogenase (LDH) release from Ang II-, Ang III-, or losartan-treated cells. LDH release is expressed as percentage of maximal LDH release induced by $1 \%$ Triton X-100 for 48 hours. ${ }^{a} p<0.05$ vs. 8 hours MCP-1 level, ${ }^{\mathrm{b}} \mathrm{p}<0.05 \mathrm{vs}$, control cells. 


\section{$\mathrm{LDH}$ release}

LDH release did not increase above control values in response to either Ang II $\left(10^{-6} \mathrm{M}\right)$, Ang III $\left(10^{-7} \mathrm{M}\right)$, or losartan $\left(10^{-7} \mathrm{M}\right)$, indicating that these agents are not cytotoxic (Fig. 3).

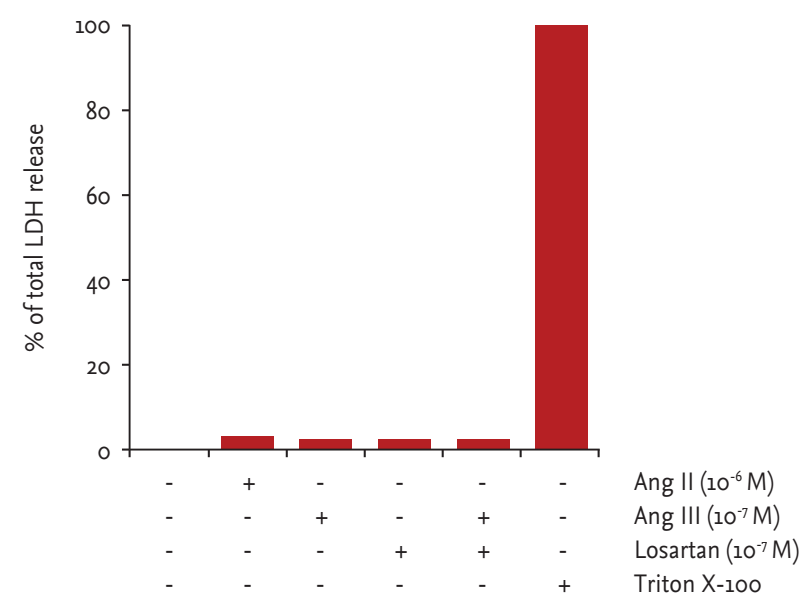

Figure 3. Lactate dehydrogenase (LDH) release from angiotensin (Ang) II-, Ang III-, or losartan-treated cells. LDH release is expressed as percentage of maximal $\mathrm{LDH}$ release induced by $1 \%$ Triton X-100 for 48 hours.

\section{Ang III stimulates p38 phosphorylation and JNK MAPK activity}

To explore whether Ang III induces the MAPK signaling pathway in $\mathrm{HK}_{2}$ cells, the phosphorylation status of $\mathrm{p} 38$, JNK, and ERK was measured in Ang III $\left(10^{-7} \mathrm{M}\right)$-treated cells by Western blot using specific antiphospho-MAPK antibodies.

p38 MAPK activity increased significantly in HK-2 cells exposed to Ang III for 30-60 minutes, with peak phosphorylation at 30 minutes $(p<0.05)$ (Fig. 4A). Total phosphorylated JNK appeared to increase suddenly 20 minutes after Ang III stimulation, but this change was not significant (Fig. 4 B). ERK protein levels tended to increase in a time-dependent manner $(p>0.05)$ (Fig. $4 \mathrm{C}$ ).

To evaluate whether inhibiting various MAPK pathways affects Ang III-induced MCP-1 expression, we measured MCP-1 levels in conditioned media of HK-2 cells pre-incubated with various MAPK inhibitors for 30 minutes and then added Ang III $\left(10^{-7} \mathrm{M}\right)$ for 48 hours. Pre-treatment with $\mathrm{p}_{3} 8$ and JNK inhibitors significantly inhibited Ang III-induced MCP-1 production $(p<0.05)$ (Fig. 5). p38

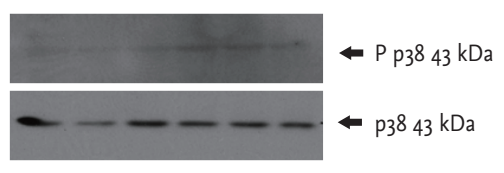

Con $5 \quad 10 \quad 20 \quad 30 \quad 60 \quad(\mathrm{~min})$

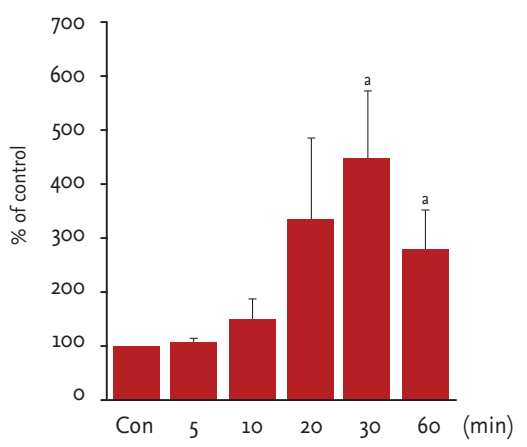

A
JNK

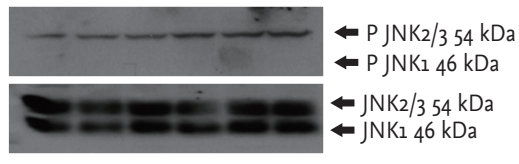

Con $5 \quad 10 \quad 20 \quad 30 \quad 60 \quad(\mathrm{~min})$

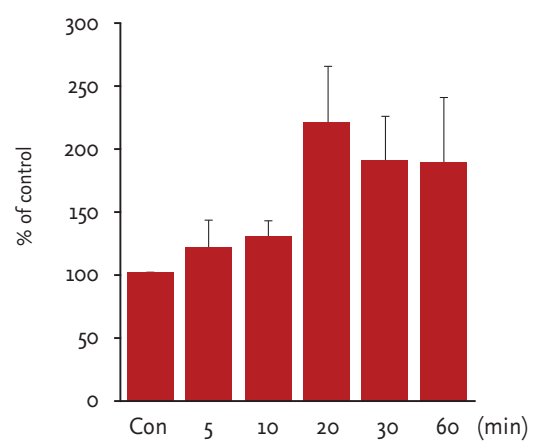

B
ERK

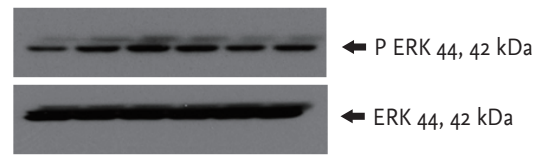

Con $5 \quad 10 \quad 20 \quad 30 \quad 60 \quad(\mathrm{~min})$

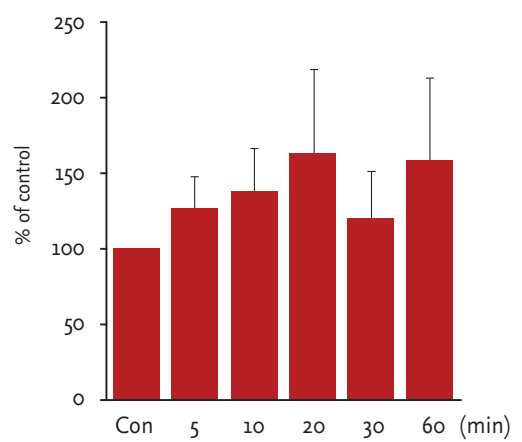

C

Figure 4. Angiotensin III (Ang III, $\left.10^{-7} \mathrm{M}\right)$ significantly stimulates p38 phosphorylation. Cells were incubated with Ang III (10 ${ }^{-7}$ M) for various times, and (A) phosphorylated p38, (B) c-Jun N-terminal kinases (JNK), and (C) extracellular signal-regulated kinases (ERK) were detected by Western blot. Results are representative of three independent experiments with similar results. Con, control. ${ }^{\mathrm{p}} \mathrm{p}<0.05$ vs. untreated cells. 


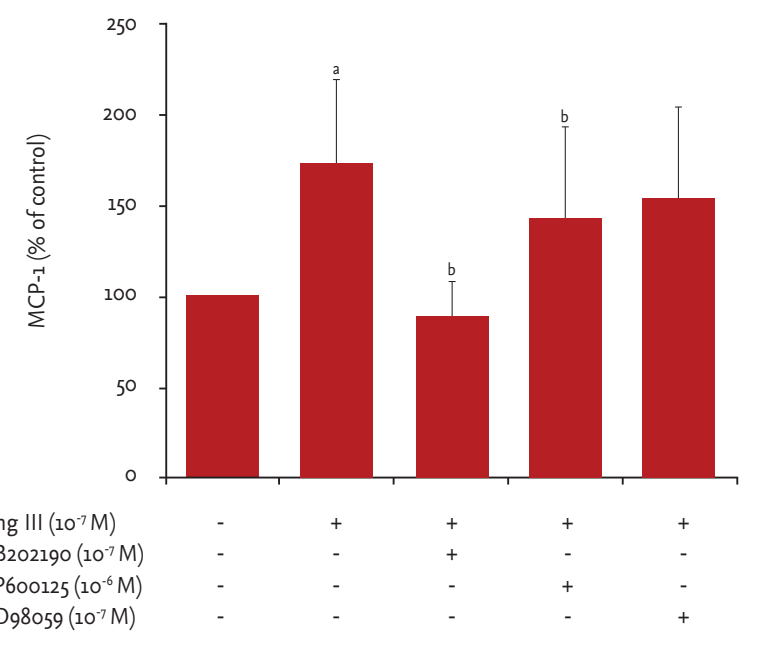

Figure 5. The effect of mitogen-activated protein kinase (MAPK) inhibitors on angiotensin III (Ang III)-induced monocyte chemoattractant protein-1 (MCP-1) production. HK-2 cells were pre-incubated with MAPK inhibitors for 30 minutes and then incubated with Ang III $\left(10^{-7} \mathrm{M}\right)$ for 48 hours. MCP-1 protein levels were measured by enzyme-linked immunosorbent assay. Results are expressed as percent increase compared to untreated cells. Results are shown as mean \pm SEM from six independent experiments. ${ }^{\mathrm{a}} \mathrm{p}<0.05$ vs. untreated cells, ${ }^{\mathrm{b}} \mathrm{p}<0.05$ vs. Ang III-treated cells.

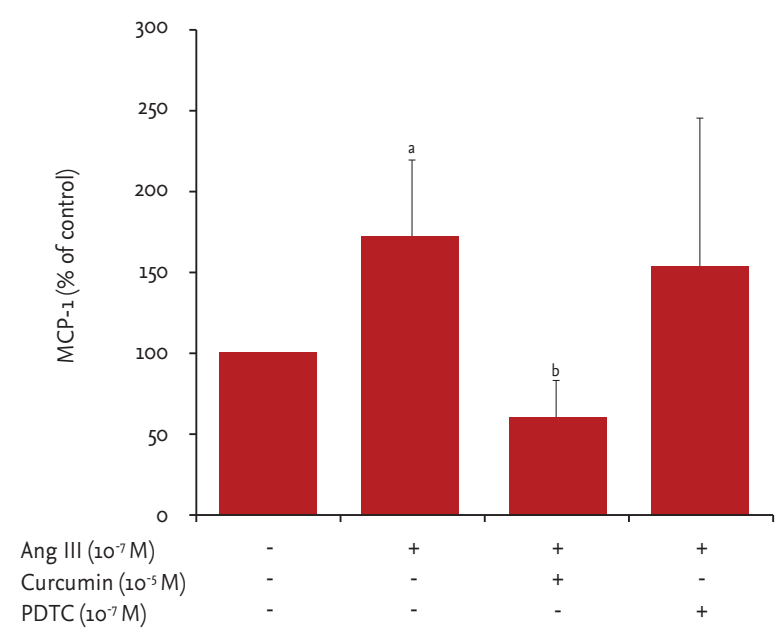

Figure 6. Effects of the transcription factor inhibitors curcumin and pyrrolidine dithiocarbamate (PDTC) on angiotensin III (Ang III)-induced monocyte chemoattractant protein-1 (MCP-1) production. HK-2 cells were pre-incubated with curcumin or PDTC for 30 minutes and then incubated with Ang III $\left(10^{-7} \mathrm{M}\right)$ for 48 hours. MCP-1 protein levels were measured by enzyme-linked immunosorbent assay. Results are expressed as percentage increase over untreated cells. Results are shown as mean \pm SEM from six independent experiments. ${ }^{a} p<0.05$ vs. untreated cells, ${ }^{b} p<0.05$ vs. Ang III-treated cells.

\section{Role of AP-1 activation in Ang III-induced MCP-1 expression}

To identify the intranuclear signaling pathway by which Ang III induces MCP-1 production, we pre-incubated cells with the c-Jun/AP-1 inhibitor curcumin and/or the NF- $\kappa$ B inhibitor PDTC for 30 minutes prior to addition of Ang III for the remaining 48 hours. MCP-1 protein levels in conditioned medium were measured by enzyme-linked immunosorbent assay. Pre-treatment with the AP-1 inhibitor significantly inhibited Ang III-induced MCP-1 production $(p<0.05)$, but the NF- $\kappa$ B inhibitor had no effect (Fig. 6).

\section{DISCUSSION}

The aim of the present study was to examine whether Ang III is involved in monocyte recruitment by regulating the chemokine MCP-1. We demonstrated that Ang III increases MCP-1 production in HK-2 cells, partly through intracellular p38 and JNK MAPK signaling activity and subsequent AP-1 transcriptional activity.

Ang II is converted to Ang III by aminopeptidase A, which cleaves the $\mathrm{NH}_{2}$-terminal aspartate group and is present in glomerular and tubular cells [30]. The Ang II level is 1,000 times higher in the lumen of proximal tubular cells than in plasma and does not detectably decrease along the length of the proximal tubule [31]. Previous studies have shown that Ang III increases the renal inflammatory response in mesangial and mononuclear cells by a mechanism dependent on NF-KB and AP-1 [30-32]. However, it is unclear whether Ang III affects the monocyte-mediated inflammatory response in human renal proximal tubule cells such as HK-2 cells [32-34].

Our results suggest that Ang III upregulates MCP-1 and contributes to the accumulation of inflammatory cells such as monocytes in proximal tubule cells. Infiltration of monocytes into the kidney is thought to play a central role in progressive inflammatory renal disease [35,36]. Therefore, inhibiting Ang III may be important in managing inflammatory kidney disease.

Increased MCP-1 levels were inhibited by adding an AT1 receptor blocker (losartan), suggesting that the inflammatory response induced by Ang III is mediated by the AT1 receptor. Some effects of Ang II are also mediated by $\mathrm{AT} 1$, such as vasoconstriction, sodium reab- 
sorption, sympathetic nerve stimulation, aldosterone secretion, and inhibition of renin synthesis [37,38]. Furthermore, Ang II binds to the AT2 receptor and contributes to the inhibitory effects mediated by AT1 [39]. In fact, which receptors Ang III acts on in renal cells is far from fully understood. Some studies show that Ang III activates NF- $\mathrm{KB}$ in cultured mesangial cells, mainly via AT2 receptors [18], and contributes to antinociception in rat brain cells via the AT1 receptor [40]. In addition, the baroreceptor reflex response at the rat nucleus tractus solitarii is modulated via both receptors [41]. It appears that Ang III has affinities to different receptor subtypes depending on the tissue and mechanism of action. Further studies are needed using selective AT1 and AT2 receptor antagonists or knockout animal models.

Aberrant or inappropriate MAPK function has been identified in many diseases, and MAPKs are ubiquitous elements in signaling pathways that control cellular functions [42]. In the present study, we evaluated the p38, JNK, and ERK MAPKs to determine which is involved in Ang III-stimulated MCP-1 production in HK-2 cells. Our results show that inhibiting p3 8 significantly decreases Ang III-induced MCP-1 production. Therefore, p38 may have a role in the intracellular signal pathway of Ang III-induced MCP-1 production in HK2 cells. Unlike ERK MAPKs, which are activated by growth factors, p38 MAPKs are responsive to stress stimuli, cytokines, and factors involved in cell differentiation and apoptosis, as are JNK MAPKs [43]. In our study, the total level of phosphorylated JNK appeared to increase suddenly 20 minutes after stimulation by Ang III, but the increase was not significant, likely due to small sample size. Additional study is needed to clarify whether JNK MAPKs also have a role in $\mathrm{MCP}-1$ production.

The 5 -flanking region of the MCP-1 gene contains multiple AP-1 and NF- $\mathrm{KB}$ binding sites, suggesting a potential role for both intranuclear transcription factors in the regulation of MCP-1 expression [44]. Ang III-induced activation of NF- $\kappa \mathrm{B}$ activity leading to increased MCP-1 expression in mesangial cells has been described previously [34]. However, this effect has not been demonstrated in proximal tubular epithelial cells. Therefore, we examined whether Ang III-induced activation of AP-1 or NF- $\mathrm{KB}$ is responsible for increased MCP-1 production in HK-2 cells.

Some studies have reported that the NF-kB and AP-1 transcription factors regulate MCP-1 expression in stimulus- and tissue-specific manners. In mesangial cells, interleukin (IL)-1 $\beta$-induced MCP-1 expression is mediated by NF-кB $[45,46]$, proteasome inhibitor-induced MCP-1 expression is mediated by the JNK/AP-1 pathway [47], and Ang III-induced MCP-1 expression is mediated by both NF-אB and AP-1 [34]. In particular, the role of AP-1 activation in the upregulation of MCP-1 expression has been described in various cells. Activation of AP-1 is required for inducing MCP-1 by IL-1 $\beta$ and shear stress in vascular endothelial cells $[48,49]$. However, no study has clearly determined whether Ang III-induced MCP-1 expression is mediated by AP-1 in proximal tubular epithelial cells such as HK-2 cells.

In our study, pre-treatment with the AP-1 inhibitor curcumin significantly inhibited Ang III-induced MCP1 production. In fact, curcumin not only inhibits DNA binding of c-Jun/AP-1 transcription factors but also downregulates c-Jun gene transcription [50]. Therefore, we explored the role of c-Jun/AP-1 in Ang III-induced MCP-1 production using this inhibitor. When HK-2 cells were pre-incubated with curcumin, Ang III-induced MCP-1 production was inhibited. However, the NF- $\kappa \mathrm{B}$ inhibitor PDTC did not block Ang III-induced MCP-1 production. These results indicate that AP-1 activation is involved in Ang III-induced MCP-1 expression. c-Jun contains a docking site for JNKs, which phosphorylates serines $6_{3}$ and 73, thereby enhancing its transcriptional activity and stability [51]. Activation of JNK or p38 MAPK results in greatly enhanced c-Jun transcriptional activity and induction of AP-1 target genes [51,52].

In conclusion, our results suggest that Ang III induces MCP-1 expression in HK-2 cells by increasing JNK and p38 activities and subsequent AP-1 activity. Our results also provide a rationale to investigate inhibition of Ang III as a potential new therapeutic target in inflammatory renal disease.

\section{KEY MESSAGE}

1. Angiotensin III (Ang III) increases monocyte chemoattractant protein-1 synthesis in HK-2 cells by stimulating p3 8 and c-Jun N-terminal kinases mitogen-activated protein kinase activities and subsequent activating protein-1 activity. 
2. Our results provide a rationale to investigate the inhibition of Ang III as a potential new therapeutic target in inflammatory renal disease.

\section{Conflict of interest}

No potential conflict of interest relevant to this article was reported.

\section{REFERENCES}

1. Igic R. A short history of the renin-angiotensin system. Acta Med Salin 2009;38:8-12.

2. Capettini LS, Montecucco F, Mach F, Stergiopulos N, Santos RA, da Silva RF. Role of renin-angiotensin system in inflammation, immunity and aging. Curr Pharm Des 2012;18:963-970.

3. Park CG, Ahn JC, Hong SJ, et al. Efficacy of irbesartan on left ventricular mass and arterial stiffness in hypertensive patients. Korean J Intern Med 2006;21:103-108.

4. Yoon HE, Choi BS. The renin-angiotensin system and aging in the kidney. Korean J Intern Med 2014;29:291-295.

5. Unger T. The role of the renin-angiotensin system in the development of cardiovascular disease. Am J Cardiol 2002;89:3A-9A.

6. Brasier AR, Recinos A 3rd, Eledrisi MS. Vascular inflammation and the renin-angiotensin system. Arterioscler Thromb Vasc Biol 2002;22:1257-1266.

7. Marchesi C, Paradis P, Schiffrin EL. Role of the renin-angiotensin system in vascular inflammation. Trends Pharmacol Sci 2008;29:367-374.

8. Suzuki Y, Ruiz-Ortega M, Lorenzo O, Ruperez M, Esteban V, Egido J. Inflammation and angiotensin II. Int J Biochem Cell Biol 2003;35:881-900.

9. Muller DN, Mervaala EM, Schmidt F, et al. Effect of bosentan on NF-kappaB, inflammation, and tissue factor in angiotensin II-induced end-organ damage. Hypertension 2000;36:282-290.

10. Ardaillou R. Active fragments of angiotensin II: enzymatic pathways of synthesis and biological effects. Curr Opin Nephrol Hypertens 1997;6:28-34.

11. Numaguchi Y, Ishii M, Kubota R, et al. Ablation of angiotensin IV receptor attenuates hypofibrinolysis via PAI-1 downregulation and reduces occlusive arterial thrombosis. Arterioscler Thromb Vasc Biol 2009;29:2102-2108.
12. Padia SH, Kemp BA, Howell NL, Fournie-Zaluski MC, Roques BP, Carey RM. Conversion of renal angiotensin II to angiotensin III is critical for AT2 receptor-mediated natriuresis in rats. Hypertension 2008;51:460-465.

13. Padia SH, Kemp BA, Howell NL, et al. Intrarenal aminopeptidase $\mathrm{N}$ inhibition augments natriuretic responses to angiotensin III in angiotensin type 1 receptor-blocked rats. Hypertension 2007;49:625-630.

14. Li Q, Feenstra M, Pfaffendorf M, Eijsman L, van Zwieten PA. Comparative vasoconstrictor effects of angiotensin II, III, and IV in human isolated saphenous vein. J Cardiovasc Pharmacol 1997;29:451-456.

15. Sjostrom H, Noren O, Olsen J. Structure and function of aminopeptidase N. Adv Exp Med Biol 2000;477:25-34.

16. Song L, Healy DP. Kidney aminopeptidase A and hypertension, part II: effects of angiotensin II. Hypertension 1999;33:746-752.

17. Song L, Ye M, Troyanovskaya M, Wilk E, Wilk S, Healy DP. Rat kidney glutamyl aminopeptidase (aminopeptidase A): molecular identity and cellular localization. Am J Physiol 1994;267(4 Pt 2):F546-F557.

18. Lorenzo O, Ruiz-Ortega M, Suzuki Y, et al. Angiotensin III activates nuclear transcription factor-kappaB in cultured mesangial cells mainly via AT(2) receptors: studies with AT(1) receptor-knockout mice. J Am Soc Nephrol 2002;13:1162-1171.

19. Ruiz-Ortega M, Lorenzo O, Egido J. Angiotensin III up-regulates genes involved in kidney damage in mesangial cells and renal interstitial fibroblasts. Kidney Int Suppl 1998;68:S41-S45.

20. Banas B, Luckow B, Moller M, et al. Chemokine and chemokine receptor expression in a novel human mesangial cell line. J Am Soc Nephrol 1999;10:2314-2322.

21. Schlondorff D, Nelson PJ, Luckow B, Banas B. Chemokines and renal disease. Kidney Int 1997;51:610-621.

22. Zhuo JL. Monocyte chemoattractant protein-1: a key mediator of angiotensin II-induced target organ damage in hypertensive heart disease? J Hypertens 2004;22:451-454.

23. Pearson G, Robinson F, Beers Gibson T, et al. Mitogen-activated protein (MAP) kinase pathways: regulation and physiological functions. Endocr Rev 2001;22:153-183.

24. Ho AW, Wong CK, Lam CW. Tumor necrosis factor-alpha up-regulates the expression of CCL2 and adhesion molecules of human proximal tubular epithelial cells through MAPK signaling pathways. Immunobiology 2008;213:533544 . 
25. Iyoda M, Shibata T, Kawaguchi M, et al. IL-17A and IL${ }_{17} \mathrm{~F}$ stimulate chemokines via MAPK pathways (ERK1/2 and $\mathrm{p} 38$ but not JNK) in mouse cultured mesangial cells: synergy with TNF-alpha and IL-1beta. Am J Physiol Renal Physiol 2010;298:F779-F787.

26. Prakash J, Sandovici M, Saluja V, et al. Intracellular delivery of the p38 mitogen-activated protein kinase inhibitor SB202190 [4-(4-fluorophenyl)-2-(4-hydroxyphenyl)-5-(4-pyridyl)1H-imidazole] in renal tubular cells: a novel strategy to treat renal fibrosis. J Pharmacol Exp Ther 2006;319:8-19.

27. Sakai N, Wada T, Furuichi K, et al. Involvement of extracellular signal-regulated kinase and p38 in human diabetic nephropathy. Am J Kidney Dis 2005;45:54-65.

28. Sheryanna A, Bhangal G, McDaid J, et al. Inhibition of $\mathrm{p}_{3} 8$ mitogen-activated protein kinase is effective in the treatment of experimental crescentic glomerulonephritis and suppresses monocyte chemoattractant protein-1 but not IL-1beta or IL-6. J Am Soc Nephrol 2007;18:1167-1179.

29. Ryan MJ, Johnson G, Kirk J, Fuerstenberg SM, Zager RA, Torok-Storb B. HK-2: an immortalized proximal tubule epithelial cell line from normal adult human kidney. Kidney Int 1994;45:48-57.

30. Yamamoto Y, Yamamguchi T, Shimamura M, Hazato T. Angiotensin III is a new chemoattractant for polymorphonuclear leukocytes. Biochem Biophys Res Commun 1993;193:1038-1043.

31. Seikaly MG, Arant BS Jr, Seney FD Jr. Endogenous angiotensin concentrations in specific intrarenal fluid compartments of the rat. J Clin Invest 1990;86:1352-1357.

32. Catalioto RM, Renzetti AR, Criscuoli M, Morbidelli L, Subissi A. Role of calcium in angiotensin II-induced prostaglandin release and DNA synthesis in rat vascular smooth muscle cells. J Cardiovasc Pharmacol 1996;27:195200.

33. Garcia-Sainz JA, Garcia-Caballero A, Gonzalez-Espinosa C. Angiotensin AT1 receptors in Clone 9 rat liver cells: Ca2+ signaling and c-fos expression. Eur J Pharmacol 1998;362:235-243.

34. Ruiz-Ortega M, Lorenzo O, Egido J. Angiotensin III increases MCP-1 and activates NF-kappaB and AP-1 in cultured mesangial and mononuclear cells. Kidney Int 2000;57:2285-2298.

35. Bohle A, Wehrmann M, Bogenschutz O, et al. The longterm prognosis of the primary glomerulonephritides: a morphological and clinical analysis of 1747 cases. Pathol
Res Pract 1992;188:908-924.

36. Segerer S, Nelson PJ, Schlondorff D. Chemokines, chemokine receptors, and renal disease: from basic science to pathophysiologic and therapeutic studies. J Am Soc Nephrol 2000;11:152-176.

37. Egido J. Vasoactive hormones and renal sclerosis. Kidney Int 1996;49:578-597.

38. Matsubara H. Pathophysiological role of angiotensin II type 2 receptor in cardiovascular and renal diseases. Circ Res 1998;83:1182-1191.

39. Naito T, Ma LJ, Yang H, et al. Angiotensin type 2 receptor actions contribute to angiotensin type 1 receptor blocker effects on kidney fibrosis. Am J Physiol Renal Physiol 2010;298:F683-F691.

40. Yang CH, Shyr MH, Tan PP, Chan SH. Participation of $\mathrm{AT} 1$ and $\mathrm{AT} 2$ receptors in the differential interaction between angiotensin II or III and alpha-2 adrenoceptors in the nucleus reticularis gigantocellularis in cardiovascular regulation and antinociception in rats. J Pharmacol Exp Ther 1996;279:795-802.

41. Luoh HF, Chan SH. Participation of AT1 and AT2 receptor subtypes in the tonic inhibitory modulation of baroreceptor reflex response by endogenous angiotensins at the nucleus tractus solitarii in the rat. Brain Res 1998;782:73-82.

42. Lawrence MC, Jivan A, Shao C, et al. The roles of MAPKs in disease. Cell Res 2008;18:436-442.

43. Faust D, Schmitt C, Oesch F, et al. Differential p38-dependent signalling in response to cellular stress and mitogenic stimulation in fibroblasts. Cell Commun Signal 2012;10:6.

44. Ueda A, Okuda K, Ohno S, et al. NF-kappa B and Spı regulate transcription of the human monocyte chemoattractant protein-1 gene. J Immunol 1994;153:2052-2063.

45. Ishikawa Y, Sugiyama H, Stylianou E, Kitamura M. Bioflavonoid quercetin inhibits interleukin-1-induced transcriptional expression of monocyte chemoattractant protein-1 in glomerular cells via suppression of nuclear factor-kappaB. J Am Soc Nephrol 1999;10:2290-2296.

46. Rovin BH, Dickerson JA, Tan LC, Hebert CA. Activation of nuclear factor-kappa B correlates with MCP-1 expression by human mesangial cells. Kidney Int 1995;48:1263-1271.

47. Nakayama K, Furusu A, Xu Q, Konta T, Kitamura M. Unexpected transcriptional induction of monocyte chemoattractant protein 1 by proteasome inhibition: involvement of the c-Jun $\mathrm{N}$-terminal kinase-activator protein 1 
pathway. J Immunol 2001;167:1145-1150.

48. Martin T, Cardarelli PM, Parry GC, Felts KA, Cobb RR. Cytokine induction of monocyte chemoattractant protein-1 gene expression in human endothelial cells depends on the cooperative action of NF-kappa B and AP-1. Eur J Immunol 1997;27:1091-1097.

49. Shyy JY, Lin MC, Han J, Lu Y, Petrime M, Chien S. The cis-acting phorbol ester "12-O-tetradecanoylphorbol 13-acetate"-responsive element is involved in shear stress-induced monocyte chemotactic protein 1 gene expression. Proc Natl Acad Sci U S A 1995;92:8069-8073.

50. Huang TS, Lee SC, Lin JK. Suppression of c-Jun/AP-1 ac- tivation by an inhibitor of tumor promotion in mouse fibroblast cells. Proc Natl Acad Sci U S A 1991;88:5292-5296.

51. Smeal T, Binetruy B, Mercola D, et al. Oncoprotein-mediated signalling cascade stimulates c-Jun activity by phosphorylation of serines 63 and 73. Mol Cell Biol 1992;12:3507-3513.

52. Sutcliffe AM, Clarke DL, Bradbury DA, Corbett LM, Patel JA, Knox AJ. Transcriptional regulation of monocyte chemotactic protein-1 release by endothelin-1 in human airway smooth muscle cells involves NF-kappaB and AP1. Br J Pharmacol 2009;157:436-450. 